\title{
ON THE REDISTRIBUTION OF EXISTING INPUTS USING THE SPHERICAL FRONTIER DEA MODEL
}

\author{
José Virgilio Guedes de Avellar \\ Armando Zeferino Milioni* \\ Tania Nunes Rabello \\ Instituto Tecnológico de Aeronáutica \\ São José dos Campos - SP, Brazil \\ avellar@ita.br \\ milioni@ita.br \\ tania@ita.br
}

\author{
Hugo Passos Simão \\ Princeton University - NJ, USA \\ hpsimao@princeton.edu
}

* Corresponding author / autor para quem as correspondências devem ser encaminhadas

Recebido em 03/2008; aceito em 04/2009 após 1 revisão

Received March 2008; accepted April 2009 after one revision

\begin{abstract}
The Spherical Frontier DEA Model (SFM) (Avellar et al., 2007) was developed to be used when one wants to fairly distribute a new and fixed input to a group of Decision Making Units (DMU's). SFM's basic idea is to distribute this new and fixed input in such a way that every DMU will be placed on an efficiency frontier with a spherical shape. We use SFM to analyze the problems that appear when one wants to redistribute an already existing input to a group of DMU's such that the total sum of this input will remain constant. We also analyze the case in which this total sum may vary.
\end{abstract}

Keywords: data envelopment analysis; constant sum of variables; efficient frontier.

\section{Resumo}

O Modelo de Fronteira Esférica (MFE) (Avellar et al., 2007) foi desenvolvido para ser usado quando se deseja distribuir de maneira justa um novo insumo a um conjunto de unidades tomadoras de decisão (DMU's, da sigla em inglês, Decision Making Units). A ideia básica do MFE é a de distribuir esse novo insumo de maneira que todas as DMU's sejam colocadas numa fronteira de eficiência com um formato esférico. Neste artigo, usamos MFE para analisar o problema que surge quando se deseja redistribuir um insumo já existente para um grupo de DMU's de tal forma que a soma desse insumo para todas as DMU's se mantenha constante. Também analisamos o caso em que essa soma possa variar.

Palavras-chave: análise de envoltória de dados; soma constante de variáveis; fronteira de eficiência. 


\section{Introduction}

Data Envelopment Analysis (DEA) is a non-parametric method developed to evaluate the relative efficiency of different entities of a common nature. Based on linear programming techniques, DEA is considered a robust tool for the evaluation of relative efficiencies as well as for the establishment of goals or benchmarks for the entities out of the efficiency border, or envelope. The analyzed entities, called Decision Making Units (DMU's), are compared under Farrell's concept of efficiency (Farrell \& Fieldhouse, 1962), which consists on a ratio of the weighted sum of outputs over the weighted sum of inputs of each DMU. The decision variables are the vector of weights of the outputs and the vector of weights of the inputs. The first DEA formulation (Charnes et al., 1978), which became well known as CCR Model, assumes constant returns to scale (CRS). The also well-known BCC Model (Banker et al., 1984) assumes variable returns to scale (VRS).

One of the purposes of a DEA formulation is to establish projections of inefficient DMU's on the efficiency border, establishing goals that would make them efficient. One way of doing that, in the so-called input-oriented models, is by decreasing the input, keeping the output constant. Similarly, in the output-oriented models, the output is increased while the input is held constant (Cooper et al., 2000).

Classic DEA models are based on freedom of action, in the sense that in order for a DMU to reach efficiency, its inputs can be decreased or outputs increased without limitations. However, there are many situations in which this freedom does not exist (Gomes et al., 2003 and Gomes et al., 2005). As an illustration, we can provide a simple but very easy to understand example related to the Olympic Games, in which countries would be considered DMU's generating medals as outputs from a fixed set of inputs. Estellita Lins et al. (2003) evaluated the results obtained by a group of countries present in the Sidney 2000 Olympic Games using DEA to rank them according to their efficiency. They used the countries' population and wealth, represented by the gross domestic product (GDP) as inputs. Since the inputs were fixed, a country that is not efficient would reach efficiency only by winning more medals. However, since the total sum of medals was fixed, a country would win an additional medal only upon the loss of that medal by another country. Problems of this nature are called DEA models with a constant sum of outputs.

In the above-mentioned paper (Estellita Lins et al., 2003) the authors used the Zero Sum Gains (ZSG) DEA model (Gomes, 2003), which can be used to allocate inputs or outputs. In ZSG, any DMU that wants to reach the efficient frontier by increasing the output (or decreasing the input) will oblige the others to reduce (or increase) their values by this amount, in order not to change the total (net gains sum is equal to zero). This increasereduce scenario is similar to a zero sum game, where all that was gained (lost) by one of the players must be lost (gained) by the others, that is the net gains sum must equal zero (see also Estellita Lins et al., 2003; Gomes et al., 2004; Gomes et al., 2005; Gomes \& Avellar, 2005 and Gomes \& Estellita Lins, 2008).

Another model that considers the constant sum of outputs constraint is the Hyperbolic Frontier (HFM) DEA model (Avellar et al., 2005), which, as opposed to ZSG, is parametric, in the sense that the efficiency frontier is assumed to follow a specific and predefined locus of points. An application of HFM on flight hour's distribution for squadrons of an Air Force can be found in Avellar (2004). 
Discussing efficient allocation of variables, Wei et al. (2000) proposed two different problems using DEA for input and output estimation called inverse DEA models. In their first formulation, they estimated the efficiency of each DMU and then they increased the input of a particular DMU up to a certain level. The authors then investigated how much additional output the DMU could produce in order to maintain its original efficiency. In the second formulation, called resource allocation problem, they increased the output and investigated how much additional input should be provided within the same purpose.

Yan et al. (2002) used the inverse DEA model to allow decision makers the possibility of incorporating their preferences over inputs/outputs into resource allocation problems.

Research is also recent for the case in which the sum of inputs is constant. According to Beasley (2003), Cook \& Kress (1999) presented the first work that reported a fixed cost allocation problem in a DEA formulation. The Cook and Kress approach is based on the idea that efficiencies should remain constant if the allocated fixed costs are treated like an input measure. They concluded that in the case of a problem with a single input and a single output, fixed costs should be distributed to each DMU in proportion to its share of total inputs. The obvious limitation of this approach is that the allocation is based only on the input measures. Thus, DMU's with the same amount of inputs will receive the same resources, independently of eventually producing different amounts of outputs.

Avellar et al. (2007) presented the Spherical Frontier DEA model (SFM), a parametric model which is used when one wants to distribute a new and fixed input to a group of DMU's. Their result considers the CRS case only. The authors claim that a fair distribution is such that all DMU's are placed on the same efficiency frontier which is assumed to exist and to have a spherical shape. The authors do succeed in showing that with the assumption that the efficiency frontier follows a specific locus of points this difficult problem becomes easy to solve, for the values of the new input to be assigned to each DMU can be calculated using a straightforward formula. An interesting feature of SFM is that the amounts assigned take into consideration the values of all other variables (input and output) present in the problem. It is also clear, however, that the spherical frontier may not be suitable to every data set. Thus, further investigation on the choices of different locus of points and on the properties of the solution associated to each choice are necessary. Gomes and Avellar compared results obtained by SFM and ZSG. They showed that, in one hand, ZSG is more general, in the sense that it can be used with constant and variable return to scale formulations and it allows weight constraints on the multipliers. On the other hand, ZSG can only be used in cases with a single input (or output) with constant sum, whereas in SFM this constraint is not necessary. Applications of SFM can be found in Avellar (2004) and Avellar et al. (2005).

There may also be situations in which one wants to redistribute an already existing input, i.e., an input for which each DMU already has a certain value. Suppose, for instance, the case of a Corporation willing to redistribute their employees into their units without firing anyone. In three recent papers, Lozano \& Villa (2004), Lozano et al. (2004) and Lozano \& Villa (2005) addressed such problems introducing the concept of "centralized" data envelopment analysis (DEA) models, which aim at optimizing the combined resource consumption by all units in an organization rather than considering the consumption by each unit separately. The authors proposed a DEA BCC model, in two phases, in which the optimization of the combined resource consumption by all units in an organization is more relevant than considering the consumption by each unit separately.

Pesquisa Operacional, v.30, n.1, p.1-14, Janeiro a Abril de 2010 
The same problem can also be solved using SFM or ZSG, as in Gomes \& Estellita Lins (2008). In every case, however, it is easy to notice that if a DMU A has to lower the number of employees to become efficient then there will be at least one DMU B which will have to increase that same input for the same purpose. But, in many cases, requiring that DMU B increases a certain input in order to be efficient may not be desirable.

Thus, the question that arises is the following: what would be the new global input value that would allow an input distribution to all DMU's in such a way that none of them would have to increase its input and, still, all of them would become simultaneously efficient, i.e., would share the same and common efficiency frontier?

Answering this question is the purpose of this article. Within the SFM context, we present a theorem in which we find this new global value taking into account all other inputs and outputs involved in the problem.

We assume throughout this paper some familiarity with DEA. Readers unfamiliar with this subject may consult Charnes et al. (1995) or Cooper et al. (2000).

The paper is organized as follows. In the next Section 1 we briefly review the main characteristics of SFM. Then, in Section 2, with the help of a numerical example, we show SFM's limitation described above and propose a theorem in order to solve this limitation. Conclusions and proposals for future research are presented in the Section 3.

\section{The Spherical Frontier Model}

The literature assures that in the case of a problem with $s$ outputs and a single input, the DEA-CCR frontier established by the ratios among the $s$ outputs and the single input has a concave shape (Cooper et al., 2000). Avellar et al. (2005) proposed the existence of a geometric place with a spherical shape in order to represent that frontier, assuring its concavity, and he called it the Spherical Frontier Model (SFM).

In SFM, among a family of spheres that represent different possible efficiency frontiers, one seeks the one for which all DMU's are placed on the same spherically shaped frontier and such that the sum of a particular input, which the authors call the "cost" assigned to each DMU, will be equal to a total fixed cost (or input) F.

The frontier shape proposed represents a CCR model, so the analyzed DMU's are supposed to have input and output values with similar magnitudes. Otherwise, the problem would be better represented by a variable return to scale model (BCC model).

The SFM formulation replaces the original piece-wise linear DEA frontier by a smooth frontier. This approach is similar to the one used by Soares de Mello et al. (2002) and Soares de Mello et al. (2004). They proposed a method to replace the original piece-wise characteristic of the DEA CCR frontier by a smooth frontier with continuous derivatives at every point, avoiding multiple solutions for the weights in the extreme-efficient points.

Another important and desirable characteristic of the SFM is that the allocation of a total and fixed input (or cost) to all DMU's takes into account all other outputs and inputs present in the model.

Let us consider the case in which we have $n$ DMU's, $s$ outputs, $m$ inputs and there is a new $\operatorname{input} f_{j}$ to be distributed among all DMU's. We call: 
$y_{r j}$ the value of output measure $r(\mathrm{r}=1, \ldots, \mathrm{s})$ for DMU $\mathrm{j}(\mathrm{j}=1, \ldots, \mathrm{n})$;

$x_{i j}$ the value of input measure $i(\mathrm{i}=1, \ldots, \mathrm{m})$ for $\operatorname{DMU~} \mathrm{j}(\mathrm{j}=1, \ldots, \mathrm{n})$;

$b_{r}$ the maximum value of output $r$ considering all DMU's;

$a_{i}$ the maximum value of input $i$ considering all DMU's;

$F$ the total fixed cost to be distributed to all DMU's;

$f_{j}$ the value of the cost to be assigned to DMU $\mathrm{j}$.

Then, Avellar et al. (2005) shows that, for s outputs,

$$
\frac{1}{R}=\frac{\left(f_{j}+\sum_{i=1}^{m} \frac{x_{i j}}{a_{i}}\right)}{\sqrt{\sum_{r=1}^{s}\left(\frac{y_{r j}}{b_{r}}\right)^{2}}}
$$

where $\mathrm{R}$ is the radius of the circumference centered at the coordinate $(0,0)$ and that the value of $f_{j}$ can be obtained by:

$$
f_{j}=\frac{\left(F+\sum_{j=1}^{n} \sum_{i=1}^{m} \frac{x_{i j}}{a_{i}}\right) \cdot \sqrt{\sum_{r=1}^{s}\left(\frac{y_{r j}}{b_{r}}\right)^{2}}}{\sum_{j=1}^{n} \sqrt{\sum_{r=1}^{s}\left(\frac{y_{r j}}{b_{r}}\right)^{2}}}-\sum_{i=1}^{m} \frac{x_{i j}}{a_{i}}
$$

\section{The problem and the proposed solution}

Consider the case of a hypothetical Corporation willing to redistribute its 3,000 employees among 7 DMU's using SFM. Consider that rent is another input variable and that production is the output.

The current values of number of employees, rent, production and CCR DEA efficiencies of those DMU's are presented in Table 1.

We use SFM (equation 2) to obtain the redistribution of the 3,000 employees and the result is showed in Table 2. Notice that rent and production are kept constant for each DMU and only the number of employees varies.

For the sake of simplicity, we will disregard the fact that the number of employees should be integer, an object of our current investigation.

Note that in the SFM solution DMU E (Table 2), which was not efficient (i.e., it was not on the original efficiency frontier), decreases its number of employees on almost $50 \%$ (from 600 to 315), whereas DMU B, for instance (among others), which was originally efficient, increases its number of employees on more than $60 \%$ (from 300 to 494). This was required so that all DMU's would become simultaneously efficient, i.e., would all be placed on the common spherically shaped efficiency frontier. 
Table 1 - Data Set.

\begin{tabular}{ccccc}
\hline DMU & $\begin{array}{c}\text { Employees } \\
\mathbf{x ~ 1 0 0}\end{array}$ & $\begin{array}{c}\text { Rent } \\
\mathbf{x} \mathbf{\$ 1 0 0}\end{array}$ & $\begin{array}{c}\text { Production } \\
\mathbf{x ~ 1 0 0 ~ i t e m s}\end{array}$ & CCR DEA Efficiencies \\
\hline A & 2.00 & 4 & 10 & $90.9 \%$ \\
B & 3.00 & 2 & 16 & $100.0 \%$ \\
C & 4.00 & 2 & 14 & $80.3 \%$ \\
D & 2.00 & 3 & 11 & $100.0 \%$ \\
E & 6.00 & 1 & 10 & $76.9 \%$ \\
F & 5.00 & 1 & 13 & $100.0 \%$ \\
G & 8.00 & 3 & 26 & $89.7 \%$ \\
TOTAL & $\mathbf{3 0 . 0 0}$ & $\mathbf{1 6}$ & $\mathbf{1 0 0}$ & \\
\hline
\end{tabular}

Table 2 - New distribution of Employees using SFM.

\begin{tabular}{ccccc}
\hline DMU & $\begin{array}{c}\text { Employees } \\
\mathbf{x ~ 1 0 0}\end{array}$ & $\begin{array}{c}\text { Rent } \\
\mathbf{x} \mathbf{\$ 1 0 0}\end{array}$ & $\begin{array}{c}\text { Production } \\
\mathbf{x ~ 1 0 0} \text { items }\end{array}$ & CCR DEA Efficiencies \\
\hline A & 2.40 & 4 & 10 & $100 \%$ \\
B & 4.94 & 2 & 16 & $100 \%$ \\
C & 4.26 & 2 & 14 & $100 \%$ \\
D & 2.99 & 3 & 11 & $100 \%$ \\
E & 3.15 & 1 & 10 & $100 \%$ \\
F & 4.17 & 1 & 13 & $100 \%$ \\
G & 8.09 & 3 & 26 & $100 \%$ \\
TOTAL & $\mathbf{3 0 . 0 0}$ & $\mathbf{1 6}$ & $\mathbf{1 0 0}$ & \\
\hline
\end{tabular}

But, as we pointed out earlier, one could argue that it may not be desirable to require that an originally efficient DMU such as DMU B increases its number of employees. In this case, it is only natural to postulate that there should be another, smaller-than-3,000 total number of employees that could be distributed to all DMU's such that they would all become efficient and none of them would have to increase its current number of employees.

Thus, our objective is to find this value, i.e., the new global value for the total number of employees that, within SFM context, allows its distribution to all DMU's in such a way that none of them has to increase its current value for that input and all of them become simultaneously efficient.

We now present a theorem in which we find this new value taking into account every output and input of all DMU's involved in the problem. 


\subsection{Theorem}

Consider a group of DMU's $j(j=1, \ldots, n)$ with constant inputs $x_{i j}(i=1, \ldots, m)$ and constant outputs $y_{r j}(r=1,2, \ldots, s)$. Suppose $x_{i j}>0$ and $y_{r j}>0$ for all $i, r$ and $j$. Let there be an additional input with initial values $f_{j}$ such that $\sum_{j=1}^{n} f_{j}=F$ and let's call $f_{j}^{0}$ the values assigned by the SFM solution, for which $\sum_{j=1}^{n} f_{j}^{0}=F$ as well. Suppose that for at least one $j$, say $j{ }^{\prime}, f_{j^{\prime}}{ }^{0}>f_{j^{\prime}}$.

Then, there is an SFM solution with input values $f_{j}^{l}$ which add up to $F^{l}<F$ and such that $f_{j}^{l} \leq f_{j}, j=1, \ldots, n$. Also, for any SFM solution with total sum of inputs $F^{2}$ such that $F>F^{2}>F^{l}$, there is at least one DMU $j$ with input value $f_{j}^{2}$ such that $f_{j}^{2}>f_{j}$, i.e., $F^{l}$ is the maximum value that assures that $f_{j}^{l} \leq f_{j}$, for all $j=1, \ldots, n$.

Proof: From (1), with $f_{j}^{0}$ and $F$ exchanging places, we have, for all $j=1, \ldots, n$ :

$$
F=\frac{\left(f_{j}^{0}+\sum_{i=1}^{m} \frac{x_{i j}}{a_{i}}\right) \cdot\left(\sum_{j=1}^{n} \sqrt{\sum_{r=1}^{s}\left(\frac{y_{r j}}{b_{r}}\right)^{2}}\right.}{\sqrt{\sum_{r=1}^{s}\left(\frac{y_{r j}}{b_{r}}\right)^{2}}}-\sum_{j=1}^{n} \sum_{i=1}^{m} \frac{x_{i j}}{a_{i}}
$$

Now, consider the anchor DMU $j^{*}$ such that $\xi_{j}$ defined as $\xi_{j}=\frac{\left(f_{j}+\sum_{i=1}^{m} \frac{x_{i j}}{a_{i}}\right)}{\sqrt{\sum_{r=1}^{s}\left(\frac{y_{r j}}{b_{r}}\right)^{2}}}$ assumes the minimum value among all $j$ 's, i.e., $\xi_{j}^{*} \leq \xi_{j}$ for all $j=1, \ldots, n$. Let's define $f_{j^{*}}{ }^{1}=f_{j^{*}}$, i.e., the new SFM solution will begin from the fact that its new output value $f_{j^{*}}{ }^{l}$ will be fixed at its current value $f_{j^{*}}$. We assumed that there is $j$, such that $f_{j^{\prime}}{ }^{0}>f_{j^{\prime}}$. From that and from (3), we have that:

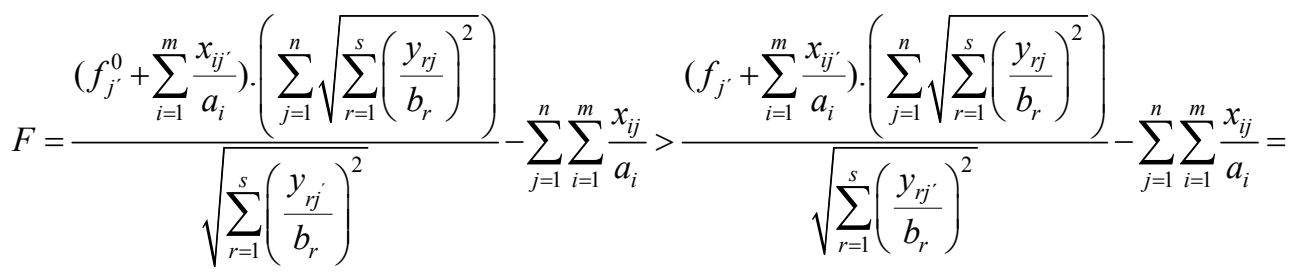

$$
\begin{aligned}
& \xi_{j^{\prime}} \cdot \sum_{j=1}^{n} \sqrt{\sum_{r=1}^{s}\left(\frac{y_{r j}}{b_{r}}\right)^{2}}-\sum_{j=1}^{n} \sum_{i=1}^{m} \frac{x_{i j}}{a_{i}} \geq \xi_{j^{*}} \cdot \sum_{j=1}^{n} \sqrt{\sum_{r=1}^{s}\left(\frac{y_{r j}}{b_{r}}\right)^{2}}-\sum_{j=1}^{n} \sum_{i=1}^{m} \frac{x_{i j}}{a_{i}}= \\
& \frac{\left(f_{j^{*}}+\sum_{i=1}^{m} \frac{x_{i j^{*}}}{a_{i}}\right) \cdot\left(\sum_{j=1}^{n} \sqrt{\sum_{r=1}^{s}\left(\frac{y_{r j}}{b_{r}}\right)^{2}}\right)}{\sqrt{\sum_{r=1}^{s}\left(\frac{y_{r j^{*}}}{b_{r}}\right)^{2}}}-\sum_{j=1}^{n} \sum_{i=1}^{m} \frac{x_{i j}}{a_{i}}=F^{1}
\end{aligned}
$$


where in the last equality above we used $f_{j^{*}}=f_{j^{*}}{ }^{1}$ and equation (2), which holds for every $j$, in particular when $j=j^{*}$. Therefore, we have proved that $F^{l}<F$.

Let's now prove that $f_{j}^{l} \leq f_{j}$ for $j=1, \ldots, n$. Using (1) we have:

$$
\begin{aligned}
& f_{j}^{1}=\frac{1}{R} \sqrt{\sum_{r=1}^{s}\left(\frac{y_{r j}}{b_{r}}\right)^{2}}-\sum_{i=1}^{m} \frac{x_{i j}}{a_{i}} \Rightarrow f_{j^{*}}^{1}=\frac{1}{R} \sqrt{\sum_{r=1}^{s}\left(\frac{y_{r j^{*}}}{b_{r}}\right)^{2}}-\sum_{i=1}^{m} \frac{x_{i j^{*}}}{a_{i}} \\
& \Rightarrow \frac{1}{R}=\frac{\left(f_{j}^{1}+\sum_{i=1}^{m} \frac{x_{i j}}{a_{i}}\right)}{\sqrt{\sum_{r=1}^{s}\left(\frac{y_{r j}}{b_{r}}\right)^{2}}}=\frac{\left(f_{j^{*}}^{1}+\sum_{i=1}^{m} \frac{x_{i j^{*}}}{a_{i}}\right)}{\sqrt{\sum_{r=1}^{s}\left(\frac{y_{r j^{*}}}{b_{r}}\right)^{2}}}=\frac{\left(f_{j^{*}}+\sum_{i=1}^{m} \frac{x_{i j^{*}}}{a_{i}}\right)}{\sqrt{\sum_{r=1}^{s}\left(\frac{y_{r j^{*}}}{b_{r}}\right)^{2}}}
\end{aligned}
$$

Then, from the definitions of $\xi_{j}$ and $j^{*}$ we have that:

$$
\frac{\left(f_{j^{*}}+\sum_{i=1}^{m} \frac{x_{i j^{*}}}{a_{i}}\right)}{\sqrt{\sum_{r=1}^{s}\left(\frac{y_{r^{*}}}{b_{r}}\right)^{2}}} \leq \frac{\left(f_{j}+\sum_{i=1}^{m} \frac{x_{i j}}{a_{i}}\right)}{\sqrt{\sum_{r=1}^{s}\left(\frac{y_{r j}}{b_{r}}\right)^{2}}} \Rightarrow \frac{\left(f_{j^{*}}+\sum_{i=1}^{m} \frac{x_{i j^{*}}}{a_{i}}\right)}{\sqrt{\sum_{r=1}^{s}\left(\frac{y_{r j^{*}}}{b_{r}}\right)^{2}}}-\frac{\left(f_{j}+\sum_{i=1}^{m} \frac{x_{i j}}{a_{i}}\right)}{\sqrt{\sum_{r=1}^{s}\left(\frac{y_{r j}}{b_{r}}\right)^{2}}} \leq 0
$$

Now, since we assumed that all inputs are positive, proving that $f_{j}^{l} \leq f_{j}$ is the same of proving that $\frac{\left(f_{j}^{1}-f_{j}\right)}{\sqrt{\sum_{r=1}^{s}\left(\frac{y_{r j}}{b_{r}}\right)^{2}}} \leq 0$.

But:

$$
\frac{\left(f_{j}^{1}-f_{j}\right)}{\sqrt{\sum_{r=1}^{s}\left(\frac{y_{r j}}{b_{r}}\right)^{2}}}=\frac{\left(f_{j}^{1}+\sum_{i=1}^{m} \frac{x_{i j}}{a_{i}}\right)}{\sqrt{\sum_{r=1}^{s}\left(\frac{y_{r j}}{b_{r}}\right)^{2}}}-\frac{\left(f_{j}+\sum_{i=1}^{m} \frac{x_{i j}}{a_{i}}\right)}{\sqrt{\sum_{r=1}^{s}\left(\frac{y_{r j}}{b_{r}}\right)^{2}}}=\frac{\left(f_{j^{*}}+\sum_{i=1}^{m} \frac{x_{i j^{*}}}{a_{i}}\right)}{\sqrt{\sum_{r=1}^{s}\left(\frac{y_{r^{*}}}{b_{r}}\right)^{2}}}-\frac{\left(f_{j}+\sum_{i=1}^{m} \frac{x_{i j}}{a_{i}}\right)}{\sqrt{\sum_{r=1}^{s}\left(\frac{y_{r j}}{b_{r}}\right)^{2}}} \leq 0
$$

In the first equality above we just added and subtracted a common term. In the second equality we used (3) and for the inequality we used (6). Thus, we have proved that $f_{j}^{l} \leq f_{j}$ for $j=1, \ldots, n$.

Finally, consider $F=F^{0}>F^{2}>F^{l}$. From (2), for all $j=1, \ldots, n$ : 


$$
\begin{aligned}
& f_{j}^{2}=\frac{\left(F^{2}+\sum_{j=1}^{n} \sum_{i=1}^{m} \frac{x_{i j}}{a_{i}}\right) \cdot \sqrt{\sum_{r=1}^{s}\left(\frac{y_{r j}}{b_{r}}\right)^{2}}}{\sum_{j=1}^{n} \sqrt{\sum_{r=1}^{s}\left(\frac{y_{r j}}{b_{r}}\right)^{2}}}-\sum_{i=1}^{m} \frac{x_{i j}}{a_{i}} \Rightarrow f_{j^{*}}^{2}=\frac{\left(F^{2}+\sum_{j=1}^{n} \sum_{i=1}^{m} \frac{x_{i j}}{a_{i}}\right) \cdot \sqrt{\sum_{r=1}^{s}\left(\frac{y_{r j^{*}}}{b_{r}}\right)^{2}}}{\sum_{j=1}^{n} \sqrt{\sum_{r=1}^{s}\left(\frac{y_{r j}}{b_{r}}\right)^{2}}}-\sum_{k=1}^{m} \frac{x_{i j^{*}}}{a_{i}}> \\
& \frac{\left(F^{1}+\sum_{j=1}^{n} \sum_{i=1}^{m} \frac{x_{i j}}{a_{i}}\right) \cdot \sqrt{\sum_{r=1}^{s}\left(\frac{y_{r j^{*}}}{b_{r}}\right)^{2}}}{\sum_{j=1}^{n} \sqrt{\sum_{r=1}^{s}\left(\frac{y_{r j}}{b_{r}}\right)^{2}}}-\sum_{i=1}^{m} \frac{x_{i j^{*}}}{a_{i}}=f_{j^{*}}^{1}=f_{j^{*}} \Rightarrow f_{j^{*}}^{2}>f_{j^{*}}
\end{aligned}
$$

So, for any SFM solution with total sum of inputs $F^{2}$ such that $F>F^{2}>F^{l}$, there is at least one DMU $j$ with input value $f_{j}^{2}$ such that $f_{j}^{2}>f_{j}$, i.e., $F^{l}$ is the minimum value that assures $f_{j^{*}}^{1}=f_{j^{*}}$ for all $j=1, \ldots, n$ and the maximum value that assures that $f_{j}^{l} \leq f_{j}$, for all $j=1, \ldots, n$.

Q.E.D.

\subsection{Theorem Application}

Applying Theorem 1 (equation 4) on data from Table 1 we obtain a new global goal for the number of employees $F^{l}=1,788$. We then distribute this number among all DMU's using SFM. The results are shown in Table 3, where we also present the initial values for the number of employees and the values obtained with the first SFM solution.

Figure 1 provides an alternative way to understand the entire process; The axes are represented by the inputs (employees and rent) divided by the single output (production). Points from the original data set (Table 1) are identified by their DMU names.

\begin{tabular}{|c|c|c|c|}
\hline DMU & Initial values $\left(f_{j}\right)$ & $\begin{array}{l}\text { SFM distribution before } \\
\text { the theorem }\left(f_{j}^{0}\right)\end{array}$ & $\begin{array}{l}\text { SFM distribution after } \\
\text { the theorem }\left(f_{j}^{l}\right)\end{array}$ \\
\hline A & 200 & 240 & 119 \\
\hline B & $300\left(f_{j}^{*}\right)$ & 494 & $300\left(f_{j}^{l^{*}}\right)$ \\
\hline $\mathrm{C}$ & 400 & 426 & 256 \\
\hline $\mathrm{D}$ & 200 & 299 & 166 \\
\hline $\mathrm{E}$ & 600 & 315 & 194 \\
\hline $\mathrm{F}$ & 500 & 417 & 259 \\
\hline G & 800 & 809 & 494 \\
\hline TOTAL & $F=3,000$ & $F=3,000$ & $F^{l}=1,788$ \\
\hline
\end{tabular}

Table 3 - Number of employees before and after applying the theorem.

Pesquisa Operacional, v.30, n.1, p.1-14, Janeiro a Abril de 2010 
Points for SFM employees redistribution keeping the initial total number $(F=3,000)$ constant are identified by their DMU names followed by a prime symbol $\left(\mathrm{A}^{\prime}, \mathrm{B}^{\prime} \ldots\right)$ and points for the SFM employees distribution in which the new global goal is given by Theorem $1\left(F^{l}=1,788\right)$ are identified by their DMU names followed by a double prime symbol (A", B”...).

The lines connecting DMU's F, B and D characterize the initial CCR efficiency frontier and define the current estimate of the Production Possibility Set (PPS). Line A'-F' connecting all prime DMU's represents the efficiency frontier after SFM employees redistribution keeping the initial total $(F=3,000)$ constant. Line A"-F" connecting all double prime DMU's represents the efficiency frontier after SFM distribution of the new global goal for the number of employees given by Theorem $1\left(F^{l}=1,788\right)$. Note that:

- Lines A'-F' and A"-F" are parallel, a consequence of the use of SFM in both cases and its hypothesis that the efficiency frontiers are represented by spheres centered at the origin (Avellar et al., 2007).

- F' falls outside of the initial estimate of the PPS. This is a characteristic of SFM. The definition of a new efficiency frontier following a specific locus of points may (not necessarily) challenge the initial estimate of the PPS, establishing goals whose feasibility depends on the nature of the process been modeled. It is a managerial task to analyze it in each particular case.

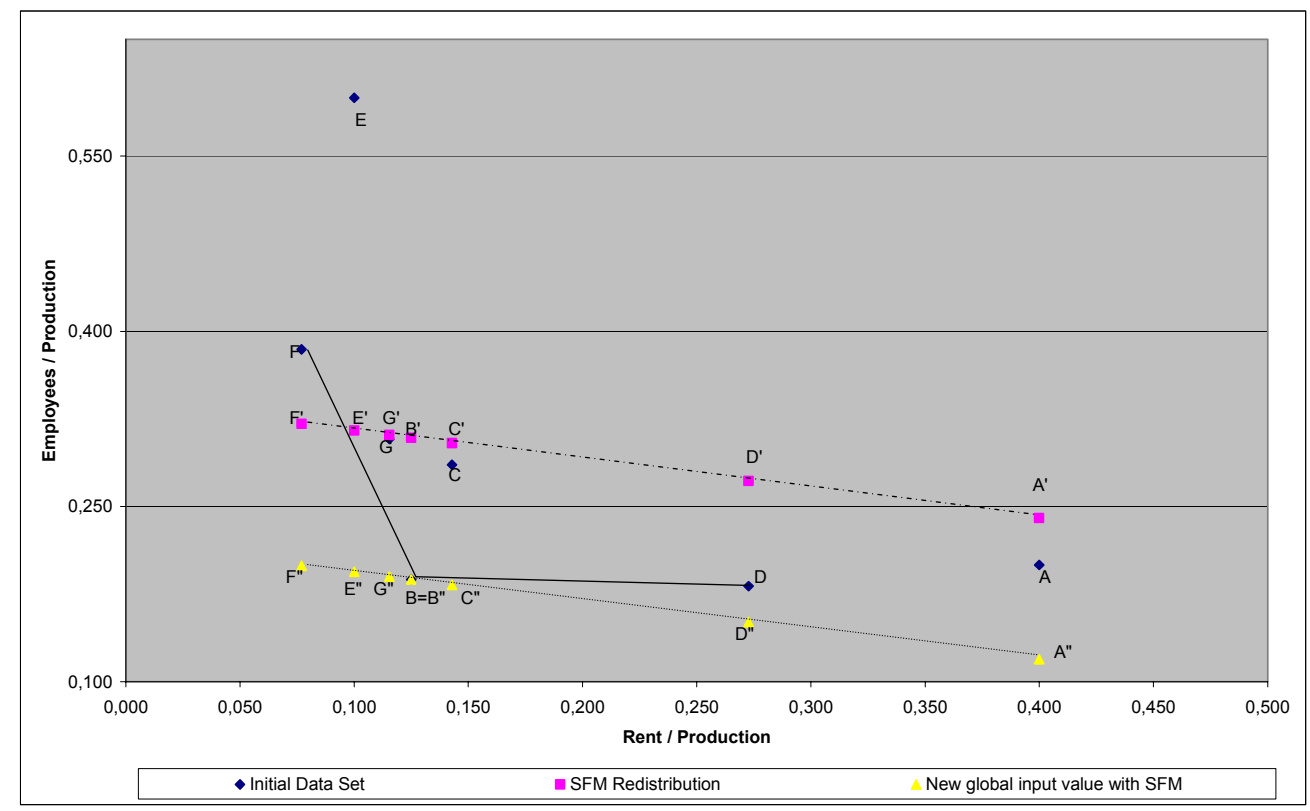

Figure 1 - Understanding the redistribution process. 
- The same rationale is taken to the limit with the help of Theorem 1. B and B" coincide, for B is the anchor DMU represented by $j^{*}$ in the proof of Theorem 1. The anchor DMU is the one that was efficient from the beginning, with the initial data set. This DMU will keep all initial data in the solution of the distribution of the new global input value computed by Theorem 1 .

- Again, however, it is necessary to admit that the individual assignments derived from the new global goal for the number of employees proposed by Theorem 1, though perfectly suitable to the anchor DMU B, may not be feasible to others DMU's.

\subsection{Further Discussion}

Another approach to solve the problem when $F$ is no longer assumed constant is using a traditional DEA formulation in which all variables are treated as nondiscretionary, with the exception of the input to be redistributed. The targets obtained for that unique input in the DEA solution would add up to a number smaller than $F$, of course, and would assure that all DMU's would be placed in the efficiency frontier.

Indeed, returning to our illustration problem, using a CCR traditional input oriented model where only input employees was allowed to vary, whereas rent and production were considered fixed, we would get targets for the input employees that added up 2,323 (see Table 4).

Table 4 - Efficiencies of SFM and DEA targets allowing reduction of inputs.

\begin{tabular}{ccccc}
\hline DMU & $\begin{array}{c}\text { SFM distribution } \\
\text { after the theorem }\end{array}$ & $\begin{array}{c}\text { Efficiencies after } \\
\text { the theorem }\end{array}$ & $\begin{array}{c}\text { Traditional DEA } \\
\text { Targets }\end{array}$ & $\begin{array}{c}\text { Efficiencies using } \\
\text { DEA Targets }\end{array}$ \\
\hline A & 119 & $100 \%$ & 182 & $100 \%$ \\
B & 300 & $100 \%$ & 300 & $100 \%$ \\
C & 256 & $100 \%$ & 262 & $100 \%$ \\
D & 166 & $100 \%$ & 200 & $100 \%$ \\
E & 194 & $100 \%$ & 290 & $100 \%$ \\
F & 259 & $100 \%$ & 500 & $100 \%$ \\
G & 494 & $100 \%$ & 590 & $100 \%$ \\
TOTAL & $\mathbf{1 , 7 8 8}$ & & $\mathbf{2 , 3 2 3}$ & \\
\hline
\end{tabular}

It is not surprising that the total value obtained with the DEA targets solution $(2,323)$ is higher than the one obtained with the theorem $(1,788)$, since the theorem imposes the additional constraint of the spherical shape of the efficiency frontier.

One immediate way for this DEA targets solution to reach the same total amount as in the solution provided by the theorem, of course, would be to multiply each input by 0.77 (i.e., 17.88/23.23), as in Table 5. This new solution could be called Adjusted DEA targets solution. 
It is obvious, however, that this solution would impose a reduction on the input value of all DMU's, including DMU B which, in the above example, was chosen by the theorem as an anchor, i.e., the benchmark for which all initial variables values would remain constant, an interesting feature of the theorem solution that cannot be reached by the Adjusted DEA targets solution.

\section{Final remarks}

The SFM DEA model is usually used when a new input, with a global constant value, is distributed in order to establish for each DMU a fraction of this input such that the total sum is the global value. However, there may be situations in which we want to distribute not a new input, but something that already exists, i.e., an input for which each DMU already has a determined value.

Table 5 - Efficiencies of SFM and DEA targets with the same total amount.

\begin{tabular}{ccccc}
\hline DMU & $\begin{array}{c}\text { SFM distribution } \\
\text { after the theorem }\end{array}$ & $\begin{array}{c}\text { Efficiencies after } \\
\text { the theorem }\end{array}$ & $\begin{array}{c}\text { Adjusted DEA } \\
\text { Targets }\end{array}$ & $\begin{array}{c}\text { Efficiencies using } \\
\text { DEA Targets }\end{array}$ \\
\hline A & 119 & $100 \%$ & 140 & $100 \%$ \\
B & 300 & $100 \%$ & 231 & $100 \%$ \\
C & 256 & $100 \%$ & 202 & $100 \%$ \\
D & 166 & $100 \%$ & 154 & $100 \%$ \\
E & 194 & $100 \%$ & 223 & $100 \%$ \\
F & 259 & $100 \%$ & 385 & $100 \%$ \\
G & 494 & $100 \%$ & 454 & $100 \%$ \\
TOTAL & $\mathbf{1 , 7 8 8}$ & & $\mathbf{1 , 7 8 8}$ & \\
\hline
\end{tabular}

We showed that in this case of input redistribution, there will be DMU's that will have to increase the current value of that input in order to be efficient and this does not seem reasonable.

We presented a theorem in which we find a new and global value that allows an input redistribution to DMU's such that none of them will have to increase its input and all become simultaneously efficient. We also showed that this approach has an interesting feature that could not be reached by the traditional DEA targets solution.

\section{References}

(1) Avellar, J.V.G. (2004). Modelos DEA com soma constante de inputs/outputs. Tese de Mestrado. Instituto Tecnológico de Aeronáutica.

(2) Avellar, J.V.G.; Milioni, A.Z. \& Rabello, T.N. (2005). Modelos DEA com variáveis limitadas ou soma constante. Pesquisa Operacional, 25(1), 135-150. 
(3) Avellar, J.V.G.; Milioni, A.Z. \& Rabello, T.N. (2007). Spherical Frontier DEA Model based on a constant sum of inputs. Journal of the Operational Research Society, 58, 1246-1251.

(4) Banker, R.D.; Charnes, A. \& Cooper, W.W. (1984). Some Models for Estimating Technical and Scale Inefficiencies in Data Envelopment Analysis. Management Science, 30, 1078-1092.

(5) Beasley, J.E. (2003). Allocating fixed costs and resources via data envelopment analysis. European Journal of Operational Research, 147, 198-216.

(6) Charnes, A.; Cooper, W.W. \& Rhodes, E. (1978). Measuring the efficiency of decision making units. European Journal of Operational Research, 2, 429-444.

(7) Charnes, A.; Cooper, W.W.; Lewin, A.Y. \& Seiford, L.M. (1994). Data envelopment analysis: Theory, methodology and applications. Kluwer Academic Publishers, Boston, USA.

(8) Cook, W.D. \& Kress, M. (1999). Characterizing an equitable allocation of shared costs: A DEA approach. European Journal of Operational Research, 119, 652-661.

(9) Cooper, W.W.; Seiford, L.M. \& Tone, K. (2000). Data Envelopment Analysis: A Comprehensive Text with Models, Applications, References and DEA - Solver Software. Kluwer Academic Publishers.

(10) Estellita Lins, M.P.; Gomes, E.G.; Soares de Mello, J.C.C.B. \& Soares de Mello, A.J.R. (2003). Olympic ranking based on a zero sum gains DEA model. European Journal of Operational Research, 148, 312-322.

(11) Farrel, M.J. \& Fieldhouse, M. (1962). Estimating efficient production functions under increasing returns to scale. Journal of the Royal Statistical Society, Series A, 252-267.

(12) Gomes, E.G. (2003). Modelos de Análise de Envoltória de dados com Ganho de Soma Zero. Tese de Doutorado em Engenharia de Produção, COPPE/UFRJ, Rio de Janeiro.

(13) Gomes, E.G.; Soares de Mello, J.C.C.B. \& Estellita Lins, M.P. (2003). Busca seqüencial de alvos intermediários em modelos DEA com soma de outputs constante. Investigação Operacional, 23(2), 163-178.

(14) Gomes, E.G.; Soares de Mello, J.C.C.B. \& Estellita Lins, M.P. (2004). Redistribuição de inputs e outputs em modelos de análise envoltória de dados com ganhos de soma zero. Pesquisa Operacional, 24(2), 269-284.

(15) Gomes, E.G. \& Avellar, J.V.G. (2005). Modelos de análise de envoltória de dados com variáveis de soma constante: teoria e aplicação. Pesquisa Naval, 18, 99-104.

(16) Gomes, E.G.; Soares de Mello, J.C.C.B. \& Estellita Lins, M.P. (2005). Uniformização da fronteira eficiente em modelos de análise de envoltória de dados com ganhos de soma zero e retornos constantes de escala. Pesquisa Operacional, 25(2), 261-277.

(17) Gomes, E.G. \& Estellita Lins, M.P. (2008). Modelling undesirable outputs with zero sum gains data envelopment analysis models. Journal of the Operational Research Society, 59, 616-623.

(18) Lozano, S.A. \& Villa, G. (2004). Centralized resource allocation using data envelopment analysis. Journal of Productivity Analysis, 22, 143-161. 
(19) Lozano, S.A.; Villa, G. \& Adenso-Diaz, B. (2004). Centralized target setting for regional recycling operations using DEA. Omega, 32, 101-110.

(20) Lozano, S.A. \& Villa, G. (2005). Centralized DEA models with the possibility of downsizing Source. Journal of the Operational Research Society, 56(4), 357-364.

(21) Soares de Mello, J.C.C.B.; Estellita Lins, M.P. \& Gomes, E.G. (2002). Construction of a smoothed DEA frontier. Pesquisa Operacional, 22(2), 183-201.

(22) Soares de Mello, J.C.C.B.; Gomes, E.G.; Biondi Neto, L. \& Estellita Lins, M.P. (2004). Suavização da fronteira DEA: o caso BCC tridimensional. Investigação Operacional, 24(1), 89-107.

(23) Wei, Q.; Zhang, J. \& Zhang, X. (2000). An inverse DEA model for inputs/outputs estimate. European Journal of Operational Research, 121, 151-163.

(24) Yan, H.; Wei, Q. \& Hao, G. (2002). DEA models for resource reallocation and production input/output estimation. European Journal of Operational Research, 136, 19-31. 